\title{
Development of an Innovative Real-World Evidence Registry for the Herpes Simplex Virus: Case Study
}

Michelle Helena van Velthoven ${ }^{1}$, BSc, MSc, PhD; Ching Lam ${ }^{1}$, MEng; Caroline de Cock ${ }^{1}$, BSc; Terese Stenfors ${ }^{2}$, BSc, MSc, PhD; Hassan Chaudhury ${ }^{3}$, BSc; Edward Meinert ${ }^{1,3}$, MA, MSc, MBA, MPA, PhD

\footnotetext{
${ }_{1}^{1}$ Digitally Enabled Preventative Health Research Group, Department of Paediatrics, University of Oxford, Oxford, United Kingdom

${ }^{2}$ Division of Surgery, Department of Clinical Sciences, Danderyd Hospital, Karolinska Institutet, Stockholm, Sweden

${ }^{3}$ Department of Primary Care and Public Health, Imperial College London, London, United Kingdom
}

\section{Corresponding Author:}

Edward Meinert, MA, MSc, MBA, MPA, PhD

Digitally Enabled Preventative Health Research Group

Department of Paediatrics

University of Oxford

Headley Way, Headington

John Radcliffe Hospital

Oxford, OX3 9DU

United Kingdom

Phone: 447824446808

Email: e.meinert14@imperial.ac.uk

\section{Abstract}

Background: Infection with the herpes simplex virus (HSV) is common but not well understood. Furthermore, there remains a social stigma surrounding HSV that can have psychosocial implications for those infected. Despite many patients infected with HSV experiencing mild-to-severe physical symptoms, only one subeffective treatment is available. A registry collecting real-world data reported by individuals potentially infected with HSV could help patients to better understand and manage their condition.

Objective: This study aimed to report on the development of a registry to collect real-world data reported by people who might be infected with HSV.

Methods: A case study design was selected as it provides a systematic and in-depth approach to investigating the planning phase of the registry. The case study followed seven stages: plan, design, prepare, collect, analyze, create, and share. We carried out semistructured interviews with experts, which were thematically analyzed and used to build use cases for the proposed registry. These use cases will be used to generate detailed models of how a real-world evidence registry might be perceived and used by different users.

Results: The following key themes were identified in the interviews: (1) stigma and anonymity, (2) selection bias, (3) understanding treatment and outcome gaps, (4) lifestyle factors, (5) individualized versus population-level data, and (6) severe complications of HSV. We developed use cases for different types of users of the registry, including individuals with HSV, members of the public, researchers, and clinicians.

Conclusions: This case study revealed key considerations and insights for the development of an appropriate registry to collect real-world data reported by people who might be infected with HSV. Further development and testing of the registry with different users is required. The registry must also be evaluated for the feasibility and effectiveness of collecting data to support symptom management. This registry has the potential to contribute to the development of vaccines and treatments and provide insights into the impact of HSV on other conditions.

(JMIR Dermatol 2020;3(1):e16933) doi: 10.2196/16933

\section{KEYWORDS}

case study; herpes simplex; herpes simplex virus vaccines; real-world evidence; patient registry 


\section{Introduction}

\section{Background}

Globally in 2012, an estimated 3.7 billion people younger than 50 years were infected with herpes simplex virus (HSV) type 1 (HSV1) and 417 million with HSV type 2 (HSV2) [1]. HSV can be contracted through oral or genital contact and is associated with symptoms of varying severity in assorted body parts, for example, painful sores on the face (cold sores), genitals (herpes), or hands [2].

HSV lies dormant in the nerves until shedding occurs, typically between 2 and 14 days after infection; however, it can take years before noticeable symptoms appear. Many individuals are unaware that they are infected with HSV as the virus often causes no or mild symptoms. The first shedding episode is generally associated with severe symptoms (eg, painful sores). Patients are typically diagnosed when symptoms are present as many methods for the diagnosis of HSV are reliant on viral shedding. The techniques for diagnosis in both symptomatic and asymptomatic periods vary in accuracy [3]. The only HSV treatment currently available is antiviral therapy (acyclovir or Zovirax), which is prescribed to patients with sores [4]. Symptomatic episodes vary in frequency between patients; some may experience one shedding episode, whereas others can have frequent painful outbreaks triggered by impaired immune responses.

Currently, no Food and Drug Administration-approved therapeutic vaccine is available for HSV [5] as the biology and biological interactions of HSVs are not comprehensively understood. It is known that HSV2 can interact biologically with HIV1; however, the implications for vaccine development require further elucidation [6]. Previous in vivo studies of HSV vaccines have been seen to prevent transmission of HSV in pigs, rodents, and primates, but they are yet to be successful in humans $[7,8]$. One therapeutic vaccine, GEN-003, was shown to reduce viral shedding and outbreaks of sores in human participants with genital HSV2 infection, but the bioscience company, Genocea, did not pursue this further [9].

The lack of available, up-to-date, high-quality, standardized data is a key barrier to efficient research, management, and treatment of HSV [10]. Clinical registries can be used to collect data about individuals with a specific diagnosis or condition on a voluntary basis. Typically, this information is contributed by health care providers following consultations with patients [11]. Clinical registries are used for data collection globally; there are more than 60 clinical registries in the United Kingdom [12] and the United States [13] and approximately 100 in Sweden [14] that have contributed to substantial research outputs and quality improvement [15].

Although clinical registries are valuable to research and treatment, clinical improvements are primarily long term, with little direct patient benefit [16]. Other limitations of current registries include the lack of privacy, anonymity, informed consent, stakeholder feedback, and awareness of existing standards and processes when building or maintaining a patient registry. In addition, clinicians may be unable or unwilling to contribute to registries because of time or technical constraints [17]. In recent decades, there has been an increasing focus on incorporating patient-reported outcomes and real-world data into clinical registries to overcome these issues [11]. Real-world evidence (RWE) is a subset of evidence-based medicine that refers to health care information gathered through means outside of typical clinical research settings. The increasing ubiquity of the internet has made it more convenient for internet-literate patients to participate in data provision and to link and analyze data for planning and managing care [18].

\section{Aim and Objectives}

Currently, there is no registry for the collection of real-world HSV data. A patient registry whereby people submit information themselves, providing real-world data on HSV, could provide more standardized and higher quality data than currently available. A patient registry is "an organised system that uses observational study methods to collect uniform data (clinical and other) to evaluate specified outcomes for a population defined by a particular disease, condition, or exposure, and that serves one or more predetermined scientific, clinical, or policy purposes" [19]. A patient registry could help individuals to understand the triggers and indications of HSV recurrences and make changes to their lifestyle to mitigate these symptoms where possible. A real-world registry could facilitate research into the development of vaccines and new, effective treatments, and examine the impact of HSV on other conditions. The aim of this study was to develop a registry to collect real-world data reported by people who might be infected with HSV. The objectives were to obtain expert opinions on important aspects of a registry and to provide insights into how specific users might use the registry.

\section{Methods}

\section{Case Study Overview}

A case study design was selected to provide a structured means to generate in-depth evidence to contribute to the further development of the proposed registry. We conducted semistructured interviews with experts and analyzed their opinions on an HSV registry to establish themes. The results of the thematic analysis were used as the basis for the development of use cases (a specific user of the registry) that will be applied to the development of an RWE registry. A traceability log was maintained in Microsoft Excel linking the research questions to data sources and the study findings.

This research project brings researchers in contact with people who gave their views on the value and development of an HSV registry. The interviewees did not provide information about themselves and the opinions that they offer were not themselves the subject of research. Therefore, in line with the University of Oxford guidance, ethical approval was not required.

\section{Case Study Framework}

The case study development followed seven stages, which are outlined in Table 1. 
Table 1. Case study framework.

\begin{tabular}{lll}
\hline Number & Stage & Outcome \\
\hline 1 & Plan & Description of case and linking of approach to outcomes. \\
2 & Design & Construction of research design and linkage of research questions, data, and criteria for evaluation and synthesis. \\
3 & Prepare & Draft, execution, and approval of study protocols. \\
4 & Collect & Conduction of semistructured interviews. \\
5 & Analyze & Thematic analysis of data. \\
6 & Create & $\begin{array}{l}\text { Development of use cases for a clinical registry website. } \\
7\end{array}$ \\
Share & $\begin{array}{l}\text { Presentation of the findings in a report for publication in a peer-reviewed journal (this paper) and sharing with registry } \\
\text { design and production team. }\end{array}$ \\
\hline
\end{tabular}

\section{Step 1: Plan}

The research question centered on investigating the potential of a registry for collecting real-world data contributed by people who might be infected with HSV. The focus of the registry was selected because evidence from the literature suggests that although infection with HSV is common, it is not well understood. Furthermore, there is no vaccine or effective treatment for HSV, leading to morbidity for individuals suffering symptoms of viral shedding. An RWE registry would help people with HSV understand their condition and contribute valuable information to the development of vaccines and treatment. A case study can be used to inform the development of an appropriate real-world registry.

\section{Step 2: Design}

We designed a case study that involved semistructured interviews with experts. The findings of these interviews were thematically analyzed. On the basis of these findings, we developed use cases that are reported in this study and will be used to design a prototype registry.

\section{Step 3: Prepare}

We produced a list of 11 experts with different backgrounds, selected by iterative discussions with a health care expert (HC, Digital Health Lead at Healthcare UK, Department for International Trade). We chose four experts who were most relevant to this case study, represented different views, and were available for an interview. The interviewees included a male and female representative (experts 1 and 2) of the Herpes Viruses Association, which provides information to people infected with HSV [19], a sexual health consultant with long-standing interest and published research in HSV therapeutics (expert 3), and a scientist working on HSV and herpes simplex encephalitis (HSE; expert 4). Participants provided verbal consent to involvement in the study, note-taking during conversations, and, in one case, the conversation being recorded. The list of interview questions was discussed in detail in a steering committee meeting and then developed through repeated review (HC; Yusuf Ermak, Director KPMG Advisory; and EM, Research Fellow in Digital Health). The final questionnaire had 48 questions and was piloted in the first interview (Multimedia Appendix 1).

\section{Step 4: Collect}

The interviews took place at a location convenient for the interviewees and lasted up to an hour. In the interviews, one researcher asked the questions and followed these up, and another researcher took notes (female research assistant Abrar Alturkistani, MPH, and male analyst Ben Southwood, MA). The researchers were experienced in conducting qualitative interviews and were knowledgeable about HSV. Although not all interviews were directly transcribed, there was a high level of agreement between the separate sets of notes of the interviews. The notes mostly comprised direct quotations and paraphrases. The notes were consolidated into a single document to code the responses into themes. Transcripts were not sent back to the participants.

\section{Step 5: Analyze}

We thematically analyzed the content of the interviews. One researcher built the themes from the first interview and reviewed, edited, and refined the themes as the interview process went on. A second independent researcher worked on the data following completion of the thematic analysis. We used this independent coder system to increase the reliability of the coding [20]. Later, we compared the two thematic analyses to determine consistent, unified themes. The final themes were not centered around any of the questions from the interviews and were instead constructed from the data [21].

Several reviews, discussions, and reconfigurations took place before finalization of a set of themes that justified the source material. After initial coding, the two researchers met on two occasions and had several phone calls to discuss differences in their coding. The themes and subthemes identified were repeatedly passed through the data until the smallest coherent and consistent set of themes that captured all the insights was reached. After agreeing on themes, the entire interview text was passed through our agreed themes. This allowed us to generate a full count of the number of times themes and subthemes appeared in the interview texts. The findings were not reviewed by the interviewees.

\section{Step 6: Create}

Having reviewed and finalized the thematic analysis of the interviews, we developed use cases for the prototype real-world registry. These were centered around four types of users with several subtypes. These use cases will inform design work regarding potential users, their motivations for use, how they 
would access features, and what they would achieve from interacting with this registry.

Step 7: Share

This paper shares the findings of the case study.

\section{Results}

\section{Semistructured Interview Findings}

A high-level summary of the key themes and subthemes identified in the interviews is provided in Table 2, followed by a detailed explanation of the themes with quotes. The key themes were stigma and anonymity, selection bias problems, understanding treatment gaps and outcomes, lifestyle factors and causes, individualized versus population-level data, and severe complications of HSV1/2.

Table 2. Interview themes, count, and subthemes.

\begin{tabular}{|c|c|c|}
\hline Theme & Subthemes & Count, $\mathrm{n}$ \\
\hline Stigma and anonymity & $\begin{array}{ll}\text { - } & \text { Root causes } \\
\text { - } & \text { Impact } \\
\text { - } & \text { Anonymity } \\
\text { - } & \text { Careful design }\end{array}$ & 12 \\
\hline Selection bias problems & $\begin{array}{ll}\text { - } & \text { Being unaware of having an } \mathrm{HSV}^{\mathrm{a}} \text { infection } \\
\text { - } & \text { Available population exaggerates seriousness } \\
\text { - } & \text { Other selection bias problems } \\
\text { - } & \text { Ways to ameliorate }\end{array}$ & 21 \\
\hline Understanding treatment and outcome gaps & $\begin{array}{ll}\text { - } & \text { Trouble getting treatment } \\
\text { - } & \text { Spatial } \\
\text { - } & \text { Differences by provider } \\
\text { - } & \text { Treatment over time }\end{array}$ & 15 \\
\hline Lifestyle factors and causes & $\begin{array}{ll}\text { - } & \text { Health and fitness } \\
\text { - } & \text { Sex and dating }\end{array}$ & 5 \\
\hline Individualized versus population-level data & $\begin{array}{l}\text { - } \quad \text { Genetics of HSV } \\
\text { - } \quad \text { Broad-based studies }\end{array}$ & 10 \\
\hline Severe complications of HSV $1 / 2$ & $\begin{array}{ll}\text { - } & \text { HIV } \\
\text { - } & \text { Herpes simplex encephalitis } \\
\text { - } & \text { Pregnancy and neonatal herpes } \\
\text { - } & \text { Pain } \\
\text { - } & \text { Other severe outcomes } \\
\end{array}$ & 23 \\
\hline
\end{tabular}

${ }^{\mathrm{a}} \mathrm{HSV}$ : herpes simplex virus.

\section{Theme 1: Stigma and Anonymity}

Interviewees mentioned that HSV is stigmatized for different reasons, including being considered a sexually transmitted infection (STI) and misinterpretation by the public. This was thought to start from sex education when people are told that catching a sexually transmitted disease is bad and disgusting. In addition, HSV1/2 has been stigmatized by the media and by many jokes about herpes from the early 1980s onward. Furthermore, people think they know that HSV is incurable, but other conditions that stay in the body like herpes are not called incurable, including thrush and chicken pox. These findings imply that better education on HSV is required to reduce the psychosocial implications of HSV infection:

General public and media need to know more-could lessen psychological impact a great deal. [Expert 1]
For stigma-related reasons, anonymity will be an important factor to consider when designing the registry as participants will likely not want their HSV infection status to be revealed. It is important not to discourage potential users; therefore, any registry must have credible security, options for anonymity, and explain data access:

Would have to be extremely discreet to get people to submit info about themselves. People join our association under assumed names, that's perfectly fine. [Expert 2]

The registry needs to be designed with the user and their experience in mind (user centricity), meaning that the data collection process serves the expectations and needs of users. In the development frameworks of existing registries, patient centricity is limited, thereby reducing utility. Lack of anonymity will result in user concerns about privacy and control over data when sensitive information is requested. In addition, it was 
thought that terms such as incurable, chronic, attack, victim, and dramatic red colors should be avoided.

\section{Theme 2: Selection Bias Problems}

The interviewees considered currently available data collection methods to be subject to selection bias problems. There are epidemiological herpes studies doing similar things as a registry but their data are not detailed, longitudinal, and broad enough. It was thought that herpes gets overrepresented by how much it bothers people and, therefore, studies might overestimate the symptoms by representing the worst cases. A patient registry could be used to register more people who are affected and people with minor symptoms who do not visit a health care professional:

\section{But I think that the beauty of a registry like this would be to catch everybody affected, even those with occasional cold sores that doesn't visit their GP or a clinic and isn't diagnosed with the condition. [Expert 4]}

A registry needs to represent a diverse body of people infected with HSV, with variable symptom frequency. Interviewees expected a registry to attract mostly those experiencing severe morbidity from HSV infection. A registry must also include those with HSV and from diverse sociodemographic backgrounds and age groups. There are an increasing number of older patients, which means that a purely app-based registry could be biased toward younger generations:

\section{App would bias things to younger people. Actually we do have quite a number of over 50 year olds who suffer from the more severe forms of HSV1-tentative links to Alzheimer's and dementia. I have a feeling we might lose out to these. True of even websites-but maybe websites an easier form. App/website combo might capture with largest swathe. [Expert 4]}

Future tools to collect HSV data must consider and address all the sources of bias. These tools must engage everyone who may have the condition and not just those with frequent recurrences, complications, pain, or psychological impacts.

Selection bias can become more profound during direct data collection as there would be a subset of users who are more likely to complete an extensive questionnaire, for example, more computer-literate people who have more time, patients with a confirmed diagnosis, and/or those with more frequent and/or severe symptoms keen on being informed on relevant clinical trials.

\section{Theme 3: Understanding Treatment and Outcome Gaps}

Interviewees indicated gaps in current HSV treatment, management, and outcomes. In the United Kingdom, if you get diagnosed at a sexual health clinic, you get treated free. This has resulted in sexual health clinics being shifted to local councils and privatized. Given the limited funds at public clinics, people with HSV are often pushed back to their general practitioner after diagnosis and early treatment. This means that ongoing treatment and follow-up can be difficult to get as patients are shunted between services. Furthermore, general practitioners are often less knowledgeable on herpes than sexual health care professionals:

\section{It can be difficult to get hold of because of the messy nature of the treatment landscape. Some patients can get thru GP and some patients can't. Some patients can repeatedly go to their sexual health clinic, some can't. [Expert 1]}

A registry that collects more data could work out who is having trouble getting treatment. In addition, it could collect follow-up data as, for example, people who receive acyclovir typically do not return to their health care professional. Efficacy of treatment is another issue, and there have been anecdotal reports on ineffectiveness or misdiagnosis. A registry should take into consideration how these current gaps could be improved by real-world data collection:
At the moment all you have is patient reflection, it has to be better than that, maybe a weekly diary. otherwise it becomes reflective and three months later they say it was like this...so it has to be real-time. [Expert 3]

A key benefit of a real-world registry would be the ability to collect data on people who are not seen in the health care system. Data on these people may reveal new insights into the transmission of HSV and what adds value for people with HSV symptoms:

Very little data on unmet need, since they don't
contact us or anybody else after they've been
diagnosed. "I've been sitting in my house for 10 years
not having relationships - thank God I found you."
Wide scale research across the general population.
[Expert 1]

\section{Theme 4: Lifestyle Factors and Causes}

The interviewees mentioned that HSV episodes are related to a low immune response, which can be influenced by lifestyle factors; however, the existing evidence is insufficient to detail the specific lifestyle factors triggering these episodes and guidance for mitigation:

\section{If people are getting too many outbreaks they may want to change their lifestyle. Cold sores is like that because you get them when you have a cold. Understanding underlying health/fitness is potentially useful. [Expert 2]}

Lifestyle factors play an important role in the spread and management of HSV. The use of collecting information regarding interaction between partners is important to consider. A registry could be used to obtain data on how long they have been living with a partner and how many times they had sex:
Don't really understand how often patients infect partners. Have indirect evidence of how quickly people get infected. Think infection diminishes in longer relations. Would be useful to know how long in relationship, how often they have sex. [Expert 3]

In addition, it was noted that dating apps are starting to move into this area, for example, reminding people about taking STI 
testing or telling other people who do not use a condom to get screened.

\section{Theme 5: Individualized Versus Population-Level Data}

The interviewees highlighted the importance of collecting data that will be useful for research. It was mentioned that there is no reliable national data on HSV1 and HSV2 estimates. The focus has been on individualized data, and it is resource intensive to obtain swabs from individual patients. Collecting general population-level data would be useful; a registry would be able to provide individualized and broad RWE. However, it was thought to not be sufficiently informative for researchers. It was thought that a registry should also include relevant family history, for example, infectious disease, immunodeficiency, ethnicity, and anything running in the family:

I think it would give you more real world angle on how effective therapies are. You would be able to work out more quickly if its effective or not. [Expert 3]

The interviewees anticipated that the medical and research community may not be interested in only information that a traditional clinical registry may provide. Links with health care services data or genetic databases may provide a more useful long-term source and breadth of data:

I think it would be great to know the genomic consequences of herpes infection, at the moment we use the natural history. [Expert 3]

\section{Theme 6: Severe Complications of Herpes Simplex Virus $1 / 2$}

The interviewees reported that the majority of HSV cases are mild and easily manageable, and HSV is usually not especially harmful to those affected. However, severe HSV cases can be debilitating, are not well understood, and require further research to improve understanding of the pathophysiology behind their occurrence. In rare cases, HSV can have costly and damaging complications (eg, HSE). HIV status will also need to be considered as HSV infection increases HIV transmission. It was thought to be gratifying for the patient to have information around why they suffer such a life-threatening disease when so many others do not:

Why do some get very strongly affected? Only 5\% is explained by us. Not all due to genetics but we don't know any of the other factors. There is no way to predict the final outcome of the patient from things we currently observe-we don't understand what the parameters are that determine the severity of the infection. We only know that as soon as patients present with a brain infection we need to give them acyclovir FAST- and severity correlates with this but not perfectly. [Expert 4]

Furthermore, newborn babies get neonatal herpes usually from the mother during birth. If a man infects a woman toward the end of pregnancy, she may actually have a baby born with severe neurological damage. It was thought that there is a rise in neonatal herpes, but it was uncertain exactly how much and not enough to be a priority in the UK health care system.

\section{Use Cases}

After completing the thematic analysis, we developed use cases, which show potential journeys of users (Table 3). The use cases are drawn from the themes, explaining how people may use the registry and database. These use cases can broadly be categorized into members of the public, patients, clinicians, and researchers. Several issues were found after an analysis of both the themes and different use cases.

People who have HSV can be categorized into three groups: those with frequent recurrences, those with mild or rare recurrences, and pregnant women at risk of transmitting the virus vertically during parturition. Those with mild or rare recurrences might be less motivated to log their data, particularly, if they have concerns around the stigma attached to HSV. To overcome selection bias, a wide body of patients needs to be reached. As the proposed HSV registry collects data directly from users, considering ways to ensure anonymity is important. It is additionally important to ask as few questions as possible to minimize the time and effort required from the participant for data collection while ensuring that the data are comprehensive.

Lifestyle factors play a major role in the spread and management of HSV. People with frequent recurrences of HSV symptoms are most likely to contribute to an HSV registry that can help them reduce the frequency and severity of symptoms that they experience compared with a registry where the data collected do not support their personal health. Those that are not infected with HSV may be interested in engaging with an HSV registry to understand the risk factors for acquiring the virus; this is particularly important for immunodeficient individuals such as those with HIV.

Researchers will be interested in using these data to advance the development of a vaccine and better treatment. To enable a population-level view, the registry needs to provide interoperability across systems and adhere to the common and widely accepted data. Clinicians will be interested in using this to improve their clinical knowledge and practice, particularly for patients with severe HSV symptoms. 
Table 3. Use cases.

\begin{tabular}{|c|c|c|c|}
\hline Use case & I am a... & I want to... & So that I can... \\
\hline \multirow[t]{3}{*}{$\begin{array}{l}\text { Person with } \mathrm{HSV}^{\mathrm{a}} \text { in- } \\
\text { fection }\end{array}$} & $\begin{array}{l}\text { Patient with HSV experiencing } \\
\text { frequent recurrences }\end{array}$ & $\begin{array}{l}\text { Keep track of my recurrences and } \\
\text { treatments }\end{array}$ & Reduce the number and severity of recurrences \\
\hline & $\begin{array}{l}\text { Patient with HSV experiencing } \\
\text { mild and/or rare recurrences }\end{array}$ & Add information to the database & Help the scientific community advance knowledge \\
\hline & Pregnant patient with HSV & Learn about neonatal HSV & Avoid transmission of HSV to my baby \\
\hline \multirow[t]{2}{*}{ Researcher } & HSV1/2 researcher & $\begin{array}{l}\text { Elucidate interactions between HSV } \\
\text { and other conditions or demographic } \\
\text { factors }\end{array}$ & $\begin{array}{l}\text { Contribute to novel research to advance the under- } \\
\text { standing of HSV among the scientific and medical } \\
\text { community }\end{array}$ \\
\hline & $\begin{array}{l}\text { Herpes simplex encephalitis re- } \\
\text { searcher }\end{array}$ & $\begin{array}{l}\text { Understand the factors related to severe } \\
\text { HSV }\end{array}$ & $\begin{array}{l}\text { Prevent HSV infection leading to severe condi- } \\
\text { tions such as encephalitis }\end{array}$ \\
\hline \multirow[t]{2}{*}{ Members of the public } & General public & $\begin{array}{l}\text { Learn basic facts and risk factors for } \\
\text { HSV }\end{array}$ & $\begin{array}{l}\text { Reduce risk of infection, understand and adopt } \\
\text { safe practices, and assuage fear and stigma about } \\
\text { HSV }\end{array}$ \\
\hline & HIV-positive member of public & $\begin{array}{l}\text { Learn how HIV and HSV1/2 interact } \\
\text { and implications for personal health }\end{array}$ & Reduce risk transmission of HIV to others \\
\hline \multirow[t]{2}{*}{ Clinicians } & General practitioner & Improve clinical insights about HSV & Optimize management of HSV \\
\hline & $\begin{array}{l}\text { Sexually transmitted infection } \\
\text { specialist clinician }\end{array}$ & $\begin{array}{l}\text { Track patients with HSV and related } \\
\text { conditions }\end{array}$ & $\begin{array}{l}\text { Ensure optimal treatment of patients and mitigate } \\
\text { the risk of severe complications }\end{array}$ \\
\hline
\end{tabular}

${ }^{\mathrm{a} H S V}$ : herpes simplex virus.

\section{Discussion}

\section{Principal Findings}

The key themes identified in the interviews were (1) stigma and anonymity of HSV, (2) selection bias, (3) understanding treatment and outcome gaps, (4) lifestyle factors and causes, (5) individualized versus population-level data, and (6) severe complications of HSV. On the basis of these themes, we developed use cases that show the potential needs and motivations of users. These can be used to explain how people may use the registry. These use cases can broadly be categorized into members of the public, individuals with HSV, clinicians, and researchers.

The themes and use cases identified in this study are consistent with the literature. The interviewees reported that HSV can have a considerable negative psychosocial impact and affect people's relationships because of the stigma surrounding HSV [22]. Other reports corroborate that although people are generally supportive of sharing their data for research, they expect their data to be anonymized [23]. However, it has been stipulated that people may be more comfortable with sharing data if they are asked by a trusted organization (eg, universities, hospitals, or disease foundations) [24]. Addressing privacy concerns is critical in the development of an HSV registry, and anonymization is required to provide a secure environment for data sharing [25].

A second issue raised by the interviewees was different sources of selection bias. Although the internet is increasingly accessible and utilized, it is not ubiquitous. Previous research has shown limited adoption in certain sociodemographic groups related to language barriers, levels of internet literacy, and geographical locations [26]. These need to be addressed to reduce selection bias and maximize the breadth of the data obtained. Another source of selection bias is that people without symptoms are generally unaware of having HSV and those with rare or mild symptoms may be less interested in enrolling and contributing data to a registry than people with severe HSV. To address these limitations, a registry must provide a meaningful return for all those contributing data to ensure the breadth of reach and minimize selection biases. A common problem in digital data collection is the inverse correlation between engagement and number of questions/steps in the user journey. This conflicts with the overarching goal of the registry to obtain a breadth and depth of demographic information from the users to maximize the potential contribution of the registry to research and trial enrollment. It will be important to ascertain the optimal balance between collecting meaningful amounts of data and the effort required from users.

A potential use of the proposed registry highlighted by the interviewees was the potential for real-world data to address current treatment and knowledge gaps. Only one treatment for HSV is currently available - prescribed at physicians' discretion, the optimal timing, duration, and effectiveness of which is uncertain for both the first onset and subsequent recurrences [27]. A registry collecting information on treatment prescription, adherence and efficacy, and timing and severity of recurrence could help to address these unknowns. Furthermore, the collection of data on the comorbidities of those infected and their HSV journey could help to shed light on the interaction of HSV with other conditions, such as Alzheimer disease and general cognitive ability $[28,29]$.

Furthermore, recurrences of HSV can be influenced by lifestyle factors; however, these are not comprehensively understood or well communicated to infected individuals. The frequency and severity of symptoms vary among those with HSV and depend on a person's age, gender, immune system, and the route of transmission and type of virus [4]. A registry could help people 
with HSV and researchers to identify the links between life events and recurrences and change their lifestyle to mitigate or prevent recurrences. It is additionally not well known why an HSV infection can lead to more serious, often debilitating complications, such as encephalitis, in rare cases [30]. A registry could be a tool to facilitate research into these areas.

The interviewees speculated that the medical and research community may not be interested in engaging with a registry that provides information comparable with a traditional registry; therefore, links with health care services data and/or genetic databases may provide a more useful long-term source of data and give it a more diverse range of use cases.

\section{Strengths and Limitations of the Study}

The case study design is a strength of this study as it supports a systematic means of observing the subject of investigation. This research provides a structured means to generate evidence to subsequently evaluate such claims by collecting baseline data for further evaluation.

The limitations of this study are that it comprises a single case study conducted in a UK context, which limits its generalizability to other settings. Only four experts were interviewed; however, they reflected different users and provided an in-depth and rigorous insight into the key issues related to an HSV real-world registry. We conducted a thorough thematic analysis of the findings of these semistructured interviews. Future work can build on our rigorous case study. We built a step-by-step working methodology, according to the principles of case study research, and consolidated all our source materials together. The findings were shared with the registry design and production team and were presented in this case study report.

\section{Further Research}

Work to further develop the user personas identified in this case study is underway. Using the agile delivery project management framework [31], the project will be delivered in four stages: discovery phase, in which we try to better understand the users and use cases, constraints and improvement opportunities; alpha phase, in which we will develop a prototype of the solution; beta phase, in which we will build the HSV registry and test and evaluate the registry with a small patient population; and the live phase, in which the registry will be available to the public and continuous iterations and improvement will be made where necessary.

We have completed the discovery phase where we identified the key factors that impact data collection quality, technological constraints, and potential improvements that can be made for HSV registries. The alpha phase is ongoing, and a prototype of the registry is being built. The results of the discovery and alpha phases will be published subsequently.

Further research is needed on testing this registry with different users and implementing and evaluating its feasibility and effectiveness of collecting data to support the development of vaccines and treatments as well as addressing numerous knowledge gaps in this field.

\section{Conclusions}

This case study reports insights from interviews for the development of an appropriate registry for real-world data contributed by people with HSV. In existing registries, user centricity is limited, which reduces people's use of the system. The motivations and expectations of users need to be taken into account when designing the system to overcome the limitations of traditional registries. The stigma associated with HSV elicits critical privacy concerns. People who might be infected with HSV need to have the option to be anonymous, and transparency regarding the use of the data is paramount. A patient registry could help those affected by HSV to better understand their condition and reduce or mitigate recurrences. Furthermore, a registry could provide researchers and clinicians with a tool to systematically collect higher quality data for studying HSV epidemiology and to evaluate the efficacy and cost-effectiveness of treatments and vaccines.

\section{Acknowledgments}

This work was funded by the European Institute of Innovation and Technology Health (grant 18654).

\section{Conflicts of Interest}

None declared.

\section{Multimedia Appendix 1}

Interview questions.

[DOCX File, 17 KB-Multimedia Appendix 1]

\section{References}

1. Looker KJ, Magaret AS, May MT, Turner KM, Vickerman P, Gottlieb SL, et al. Global and regional estimates of prevalent and incident herpes simplex virus type 1 infections in 2012. PLoS One 2015 Oct 28;10(10):e0140765 [FREE Full text] [doi: 10.1371/journal.pone.0140765] [Medline: 26510007]

2. Li C, Li Y, Yang Y, Wang J, Zhu C, Tang S, et al. The detection and characterization of Herpes Simplex Virus Type 1 in confirmed measles cases. Sci Rep 2019 Sep 4;9(1):12785 [FREE Full text] [doi: 10.1038/s41598-019-48994-5] [Medline: 31484944] 
3. Arshad Z, Alturkistani A, Brindley D, Lam C, Foley K, Meinert E. Tools for the diagnosis of Herpes Simplex Virus 1/2: systematic review of studies published between 2012 and 2018. JMIR Public Health Surveill 2019 May 23;5(2):e14216 [FREE Full text] [doi: 10.2196/14216] [Medline: $\underline{\text { 31124465] }}$

4. Johnston C, Corey L. Current concepts for genital Herpes Simplex Virus infection: diagnostics and pathogenesis of genital tract shedding. Clin Microbiol Rev 2015 Nov 11;29(1):149-161. [doi: 10.1128/cmr.00043-15]

5. Srivastava R, Roy S, Coulon PG, Vahed H, Prakash S, Dhanushkodi N, et al. Therapeutic mucosal vaccination of Herpes Simplex Virus 2-infected guinea pigs with ribonucleotide reductase 2 (RR2) protein boosts antiviral neutralizing antibodies and local tissue-resident CD4 and CD8 T cells associated with protection against recurrent genital herpes. J Virol 2019 May 01;93(9):803-805 [FREE Full text] [doi: 10.1128/JVI.02309-18] [Medline: $\underline{\text { 30787156] }}$

6. Schiffer JT, Gottlieb SL. Biologic interactions between HSV-2 and HIV-1 and possible implications for HSV vaccine development. Vaccine 2019 Nov 28;37(50):7363-7371 [FREE Full text] [doi: 10.1016/j.vaccine.2017.09.044] [Medline: 28958807]

7. Johnston C, Koelle D, Wald A. HSV-2: in pursuit of a vaccine. J Clin Invest 2011 Dec;121(12):4600-4609 [FREE Full text] [doi: 10.1172/JCI57148] [Medline: 22133885]

8. Johnston C, Gottlieb S, Wald A. Status of vaccine research and development of vaccines for herpes simplex virus. Vaccine Internet(26)?2952 2016;34:2948 [FREE Full text] [doi: 10.1016/j.vaccine.2015.12.076]

9. Flechtner J, Long D, Larson S, Clemens V, Baccari A, Kien L, et al. Immune responses elicited by the GEN-003 candidate HSV-2 therapeutic vaccine in a randomized controlled dose-ranging phase 1/2a trial. Vaccine 2016 Oct 17;34(44):5314-5320. [doi: 10.1016/j.vaccine.2016.09.001] [Medline: 27642130]

10. Jørgensen LK, Dalgaard LS, Østergaard LJ, Nørgaard M, Mogensen TH. Incidence and mortality of herpes simplex encephalitis in Denmark: a nationwide registry-based cohort study. J Infect 2017 Dec;74(1):42-49. [doi:

10.1016/j.jinf.2016.09.004] [Medline: 27717782]

11. Trotter JP. Patient registries: a new gold standard for 'real word' research. Ochsner J 2002;4(4):211-214 [FREE Full text] [Medline: 22826660]

12. National Health Service. Clinical audits and registries URL: https://digital.nhs.uk/data-and-information/ clinical-audits-and-registries [accessed 2020-02-04]

13. US National Institutes of Health. List of Registries URL: https://www.nih.gov/health-information/ nih-clinical-research-trials-you/list-registries [accessed 2020-02-04]

14. Swedish Research Council. Registerforskning URL: https://www.registerforskning.se/en/ [accessed 2020-02-04]

15. Feltelius N, Gedeborg R, Holm L, Zethelius B. Utility of registries for post-marketing evaluation of medicines. A survey of Swedish health care quality registries from a regulatory perspective. Ups J Med Sci 2017 Mar 03;122(2):136-147. [doi: 10.1080/03009734.2017.1285837]

16. Al-Rubeaan KA, Youssef AM, Subhani SN, Ahmad NA, Al-Sharqawi AH, Ibrahim HM. A web-based interactive diabetes registry for health care management and planning in Saudi Arabia. J Med Internet Res 2013 Sep 09;15(9):e202 [FREE Full text] [doi: 10.2196/jmir.2722] [Medline: 24025198]

17. Wright A, McGlinchey EA, Poon EG, Jenter CA, Bates DW, Simon SR. Ability to generate patient registries among practices with and without electronic health records. J Med Internet Res 2009 Aug 10;11(3):e31 [FREE Full text] [doi: 10.2196/jmir.1166] [Medline: 19674961]

18. Ashley L, Jones H, Thomas J, Newsham A, Downing A, Morris E, et al. Integrating patient reported outcomes with clinical cancer registry data: a feasibility study of the electronic Patient-Reported Outcomes From Cancer Survivors (ePOCS) system. J Med Internet Res 2013 Oct 25;15(10):e230 [FREE Full text] [doi: 10.2196/jmir.2764] [Medline: 24161667]

19. Gliklich RE, Dreyer NA. In: Leavy MB, editor. Registries for Evaluating Patient Outcomes: A User's Guide. Rockville, Maryland, United States: Agency for Healthcare Research and Quality; Apr 2014.

20. Herpes Viruses Association. URL: https://herpes.org.uk/ [accessed 2020-02-04]

21. Gorden R. Basic Interviewing Skills. Itasca, Illinois: Peacock Publishers; 1992.

22. Braun V, Clarke V. Using thematic analysis in psychology. Qual Res Psychol 2006 Jan;3(2):77-101. [doi: 10.1191/1478088706qp063oa]

23. Merin A, Pachankis JE. The psychological impact of genital herpes stigma. J Health Psychol 2010 Jul 23;16(1):80-90. [doi: $10.1177 / 1359105310367528]$

24. El Emam K, Rodgers S, Malin B. Anonymising and sharing individual patient data. Br Med J 2015 Mar 20;350:h1139 [FREE Full text] [doi: 10.1136/bmj.h1139] [Medline: 25794882]

25. Nass SJ, Levit LA, Gostin LO. Beyond the HIPAA Privacy Rule: Enhancing Privacy, Improving Health Through Research. Bethesda, Maryland, United States: National Institutes of Health; 2009.

26. European Medicines Agency. Data anonymisation -a key enabler for clinical data sharing URL: https://www.ema.europa.eu/ en/documents/report/report-data-anonymisation-key-enabler-clinical-data-sharing_en.pdf [accessed 2020-02-04]

27. Blank G, Duton W. University of Oxford. Perceived Threats to Privacy Online: The Internet in Britain Internet URL: https:/ loxis.oii.ox.ac.uk/wp-content/uploads/sites/43/2019/09/OxIS-report-2019-final-digital-PDFA.pdf [accessed 2020-02-04]

28. Arduino PG, Porter SR. Oral and perioral herpes simplex virus type 1 (HSV-1) infection: review of its management. Oral Dis 2006 May;12(3):254-270. [doi: 10.1111/j.1601-0825.2006.01202.x] [Medline: 16700734] 
29. Looker KJ, Elmes JA, Gottlieb SL, Schiffer JT, Vickerman P, Turner KM, et al. Effect of HSV-2 infection on subsequent HIV acquisition: an updated systematic review and meta-analysis. Lancet Infect Dis 2017 Dec;17(12):1303-1316 [FREE Full text] [doi: 10.1016/S1473-3099(17)30405-X] [Medline: 28843576]

30. Itzhaki RF, Lathe R. Herpes viruses and senile dementia: first population evidence for a causal link. J Alzheimers Dis 2018;64(2):363-366. [doi: 10.3233/JAD-180266] [Medline: 29889070]

31. Whitley RJ, Kimberlin DW. Herpes simplex encephalitis: children and adolescents. Semin Pediatr Infect Dis 2005 Jan;16(1):17-23. [doi: 10.1053/j.spid.2004.09.007] [Medline: 15685145]

\section{Abbreviations \\ HSE: herpes simplex encephalitis \\ HSV: herpes simplex virus \\ HSV1: herpes simplex virus type 1 \\ HSV2: herpes simplex virus type 2 \\ RWE: real-world evidence \\ STI: sexually transmitted infection}

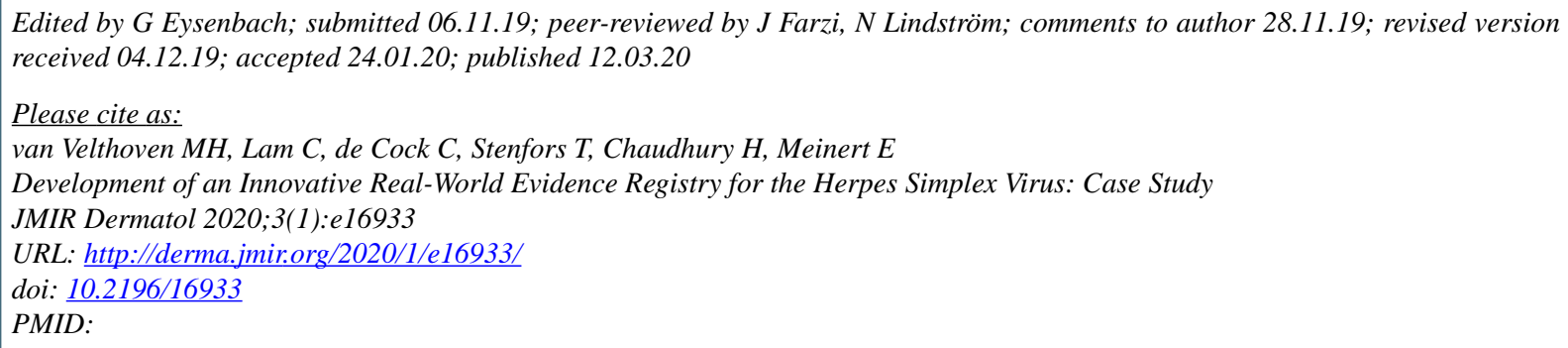

CMichelle Helena van Velthoven, Ching Lam, Caroline de Cock, Terese Stenfors, Hassan Chaudhury, Edward Meinert. Originally published in JMIR Dermatology (http://derma.jmir.org), 12.03.2020. This is an open-access article distributed under the terms of the Creative Commons Attribution License (https://creativecommons.org/licenses/by/4.0/), which permits unrestricted use, distribution, and reproduction in any medium, provided the original work, first published in JMIR Dermatology Research, is properly cited. The complete bibliographic information, a link to the original publication on http://derma.jmir.org, as well as this copyright and license information must be included. 